\title{
Luxury wine brand visibility in social media: an exploratory study
}

Mignon Reyneke

Division of Industrial Marketing, eCommerce and Logistics, Lulea University of Technology, Lulea, Sweden

Leyland Pitt

Luxury wine
brand visibility

Simon Fraser University, Vancouver, Canada and
Leeds University Business School, Leeds, UK, and

Pierre R. Berthon

McCallum Graduate School of Business, Bentley University, Waltham, Massachusetts, USA

\begin{abstract}
Purpose - The purpose of this paper is to address the visibility of luxury wine brands, in particular the Bordeaux first growth brands in social media.

Design/methodology/approach - The paper uses data from howsociable.com to portray similar luxury wine brands in multi-dimensional space. To identify the associations between the brands and the social media visibility indicators, the paper uses correspondence analysis.

Findings - The findings of the paper show that some of the brands considered did not, at the time the data were gathered, have a clearly defined social media strategy.

Practical implications - The indication is that there are opportunities for luxury wine brand managers to use social media as a tool in their marketing strategies; also some threats may exist to these brands should they take a laissez faire approach to social media, particularly when social media are becoming as influential, if not more so than conventional media.

Originality/value - Brands can take directions in social media today that would have been unlikely if not impossible five years ago. While brand managers may not fully be able to control the destinies of these brands, this paper suggests that the approaches followed in this particular research will present brand managers with a tool that will assist them in directing conversations that occur around their brands.
\end{abstract}

Keywords Wines, Brand management, Social networking sites

Paper type Research paper

The ascendance of social media

In mid-May 2010, the BBC reported that the video hosting site YouTube was getting more than two billion hits daily, and that that was nearly double the number of people who tune into the USA's three prime time TV stations combined (Shiels, 2010). YouTube had been established in 2005, and two important milestones were reached in the beginning of 2010. Earlier in 2010, YouTube had announced that every minute, 24 hours of video content were being uploaded to its servers (http://youtube-global.blogs pot.com/). The social network platform Facebook was not only larger in terms of population than most of the world's nations, by early 2010 it was second only to the search engine Google in number of daily online hits, and users spent much more time

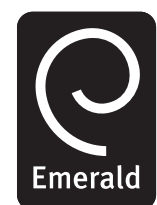

Received June 2010 Revised October 2010 Accepted October 2010 
IJWBR

23,1

22

on it. Generation Y (those born in 1976 and up to 1999) is now using Facebook as an alternative to e-mail. In February 2010, while Google got 154 million people for an hour, according to A.C. Nielsen research, 118 million people spent 6.5 hours each on Facebook (Arington, 2010), making Facebook a much "stickier" (i.e. where people spent the most time) site than Google.

Social media are now as influential, if not more so than, conventional media. This has a massive impact on brands, as witnessed in recent times by Unilever's Dove "Real Beauty" campaign (Deighton, 2007), and the Greenpeace versus Nestle Kit Kat Palm Oil debacle. While an understanding of social media is obviously important to brands and those who manage them, some key questions remain unanswered, both from the perspective of those who study brands (brand management scholars) and those who direct their fortunes (brand managers). These would include questions such as: how do we find out what is being said about a brand in social media? What is being said about competitor brands, and how is that different from our brand? Is our brand more visible in some social media than others, and how does that differ to our competitors? Anyone with knowledge and experience of social media would know that this is difficult enough to achieve on one social medium - it requires a regular tracking of what is being said - spending time on Facebook, or following Twitter tweets. Answering the question becomes even more difficult when one realizes that there is a plethora of social media out there, all of which may be communicating about a particular brand to a greater or lesser extent.

These are the issues we address in this paper. We proceed as follows: first, we provide a brief general overview of the social media phenomenon, and distinguish between the various types of social media. Second, we describe a tool for simultaneously collecting brand visibility information, called How Sociable. Then we briefly describe a study of the relative positioning of luxury wine brands (we chose the classic Bordeaux premier crus, or "first growths") based on data from How Sociable. We explain the use of correspondence analysis to simultaneously portray the various luxury wine brands in multi-dimensional space, so that they can be contrasted with each other in terms of their visibility in social media. We also comment on the current state of positioning of these brands in social media. The paper concludes with an acknowledgement of the limitations of the approach followed here, an outlining of the implications for brand managers, and an identification of avenues for future research in this domain.

\section{Social media: a brief overview}

Social media may be defined as media designed to be disseminated through social interaction between individuals and entities such as organizations. Typically they are created using highly accessible (easy to get to) and scalable (can be used to reach large numbers) publishing techniques (Brogan, 2010; Zarella, 2010). Social media use internet and web-based technologies to transform broadcast media monologues (one to many) into social media dialogues (many to many). They support the democratization of knowledge and information, transforming individuals from mere content consumers into content producers. Kaplan and Haenlein (2010) describe social media as "a group of Internet-based applications that build on the ideological and technological foundations of Web 2.0, and that allow the creation and exchange of user-generated content". Businesses and practitioners sometimes refer to social media as user-generated content or consumer-generated media, or when consumers create ads about brands they either love or hate, as consumer-generated advertising (Berthon et al., 2008). 
In many ways social media have not only changed the way in which organizations and their brands interact with their customers, it has also changed the way business gets done. Organizations are now not only able to reach customers online and interact with them, they are also able, if this is managed effectively, to become part of customer conversations. Brands are attempting to utilize social media to reach existing customers, gain new ones, and build or maintain credibility and reputation. Kaplan and Haenlein (2010) distinguish social media as having three components, namely, concept (art, information, or meme); media (physical, electronic, or verbal); and social interface (intimate direct, community engagement, social viral, electronic broadcast or syndication, or other physical media such as print).

Social media are all part of the phenomenon known as "Web 2.0". Web 2.0 is probably best viewed as a series of application progressions over Web 1.0, rather than as something new in and of itself. Web 2.0 is the internet's "now" to Web 1.0 as the internet's "then" - it is much more to do with what people are doing with the technology than the technology itself. Rather than merely retrieve information, users now create and consume it, and hence add value to the web sites that permit them to do so. These web sites usually provide a richer context to users, by means of user-friendly interfaces that encourage and facilitate participation. Tapscott and Williams (2007) contend that the economy of "the new web" depends on mass collaboration, with economic democracy as an outcome. The notion of individuals simultaneously creating value for themselves and others through profound network effects has not gone unnoticed by entrepreneurs - both for-profit business people, and social entrepreneurs, who see the technology as a way of being innovative and proactive.

Zhu et al. (2009) extended the work of Rao et al. (2003), who proposed a stage model to reflect the progression that small businesses (such as wineries) follow in their use of internet technologies. They did this first, by introducing marketing integration into a technology-focused model and further differentiating the transactions stage of the framework. They then used the model to explore differences in the degree of sophistication of Canadian winery web sites. However, this study did not focus to any extent on the se of social media by wine marketers. According to Stricker et al. (2003), from 90 to 100 percent of US wineries do have an online presence, however, this seems limited in many cases to a Web 1.0 approach. Similarly, a study by Thach (2009) on US wineries adoption of Web 2.0 components (or Wine 2.0 as she titles it), shows that these wineries have not adopted Wine 2.0 to a great extent at this point in time. She argues that irrespective of whether wineries want to adopt Web 2.0, "it is already an active relationship marketing tool generated by the consumer". As a result, marketers are encouraged to be involved in online interactions and to monitor conversations about their brands.

Because social media are a relatively novel media format, as far as we are aware there is no readily accepted classification or categorization scheme that exists to distinguish them. In what follows, we briefly describe some of the major types of social media, but do not claim that this is in any sense a definitive or even complete classification as this was not the purpose of the study. We distinguish briefly here between blogs, micro-blogs, social network sites, picture sharing, video sharing, and social news web sites.

Blogs (short for "web logs") are web sites, owned and written by individuals, who maintain regular commentaries and diaries that may include text, graphics and video, links to other blogs and web pages, usually in reverse chronological order. Rudimentary blogs function simply as personal online diaries, but more sophisticated bloggers
Luxury wine
brand visibility

23 
IJWBR

23,1

\section{4}

concentrate as commentators on a range of focused phenomena, with news and views on particular subjects, covering a wide range of industries, products, services, and special interests. Many blogs permit readers to leave their comments in an interactive format. Some specialized bloggers use their blogs to differentiate themselves from mainstream media; others are like more traditional journalists who see blogs as an alternative or additional communication channel (Steyn et al., 2008). One of the best known blog hosting sites is Google Blog Posts.

Micro-blogs are social networking services that enable its users to send and read very short messages, usually restricted by the number of characters in the message. The best known of these is Twitter, through which users can send messages known as "tweets" text-based posts of up to 140 characters displayed on the author's profile page and delivered to the author's subscribers who are known as followers. Senders can restrict delivery to those in their circle of friends or, by default, allow open access. Users can send and receive tweets via the Twitter web site, text messaging on cell phones, or external applications. Twitter has gained much prominence in the recent past. For example, during the 2009 Victorian bushfires, the Prime Minister of Australia, Kevin Rudd used his Twitter account to send out information on the fires, how to donate money and blood, and where to seek emergency help. In June 2009, following allegations of fraud in the Iranian presidential election, protesters used Twitter as a rallying tool and as a method of communication with the outside world after the government blocked several other modes of communication.

Social networking web sites are services on which users can find and add friends and contacts, and send them messages, and update their personal profiles to notify friends, contacts or colleagues about themselves. Additionally, on some social networking web sites, users can join networks organized by workplace, school, or college. The best known "friendship" social networking sites are Facebook and MySpace, and the best known professional social networking sites are LinkedIn and Plaxo. Facebook currently has more than 400 million active users worldwide (Facebook, 2010).

Picture sharing web sites, the best known of which are Flickr, Yahoo Images, and Google Images (Google I) allow users to store and share images.

Video sharing web sites allow users to upload and share videos. Typically, unregistered users can watch the videos, while registered users are permitted to upload an unlimited number of videos. The best known of the video sharing web sites is YouTube. It was estimated that in 2007 YouTube consumed as much bandwidth as the entire internet in 2000 (Daily Telegraph, 2008), and that by March 2008, YouTube's bandwidth costs were estimated at approximately US\$1 million a day (Yen, 2008).

Finally, social news web sites are sites that allow people to discover and share content from anywhere on the internet, by submitting links and stories, and voting and commenting on submitted links and stories. The best known of these is Digg (www.digg.com).

\section{Gathering brand visibility data in social media: how sociable}

It would be important for those who manage brands to have a good idea of what is being said about these brands in social media, how frequently it is being said, and in what particular media it is being said. This type of data would give the brand manager an indication of the "visibility" of the brand in social media. In most cases, the brand manager would be interested in the social media visibility of their own brand, but would probably also want to make comparisons with the performance of similar 
or competitive brands. The data could be gathered in one of two ways. First, someone could be given the responsibility of trawling through vast amounts of data in the vast numbers of posts on the various social media platforms and counting and documenting this information. Alternatively, the data could be obtained from a service that regularly trawls through social media electronically, and compiles and counts a brand's visibility. One of these types of services is a web site called How Sociable (www.howsociable.com).

How Sociable is a free service that tracks the visibility of any brand in 32 different social media, providing a score for the visibility on each, as well as an overall "visibility" score. Simply by entering the brand name into a check box on the web site, the user can obtain an overall visibility score and as well as visibility scores across the 32 different social media sites.

The overall visibility score assigned to a brand provides a quick way to compare the visibility of one brand to another. According to the site (Markwell, 2010) a visibility score is calculated by taking a set of benchmark results using one globally recognized traditional brand and giving it a score of 1,000. To ensure that even small, local brands will have a chance of scoring, they use a sliding scale. For example, a brand such as Coca-Cola has around 8,000 times more photos mentioning it on the photo sharing site Flickr compared to another brand, but the other brand will still get a score of ten for having some photos rather than getting zero.

In Figure 1, we illustrate the How Sociable brand visibility scores of ten different well-known brands recently calculated on How Sociable. For purposes of illustration we chose the five most valuable brands in the world according to the annual Interbrand report on brand values, namely Coca Cola, IBM, Microsoft, GE, and Nokia (www.interbrand.com), and also five well-known social media brands, namely Google, Facebook, Twitter, YouTube, and MySpace. All these brands were chosen simply

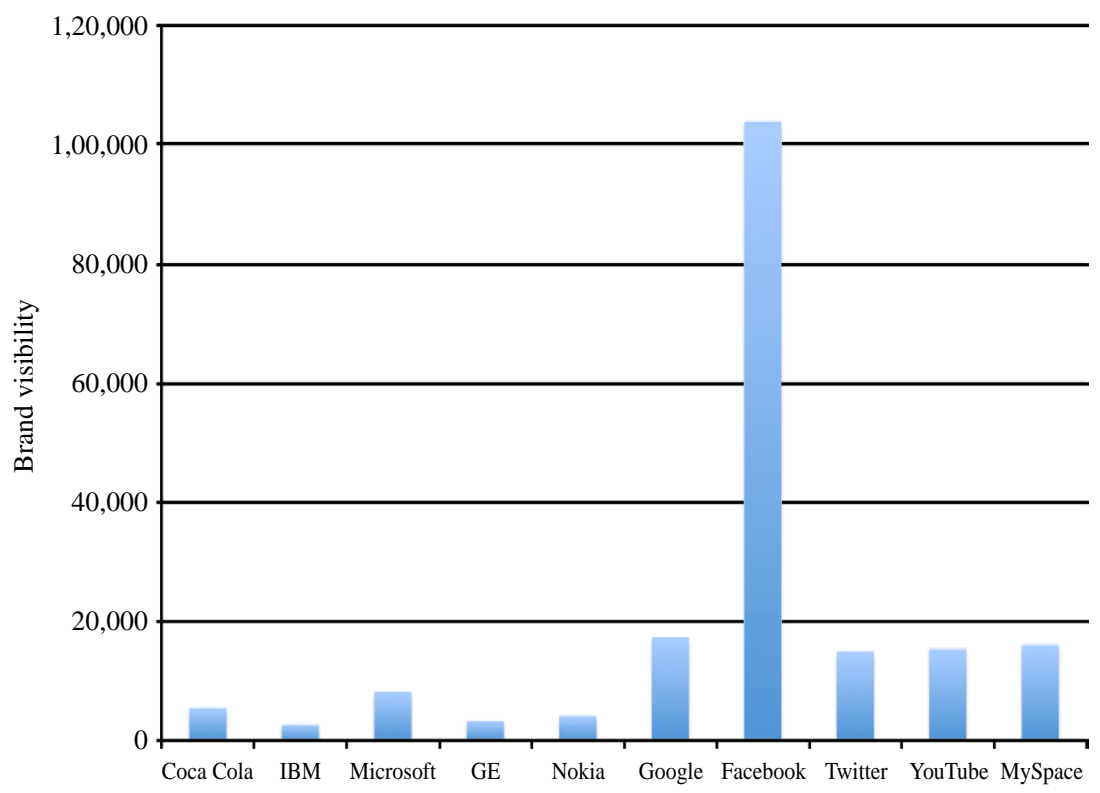

\section{Luxury wine brand visibility}

25
Figure 1. An illustration of brand visibility scores - most valuable brands and well-known social media brands 
IJWBR

23,1

26 for purposes of illustration, rather than as an endorsement of the Interbrand brand valuation methodology.

A few things that are worth noting from Figure 1 include that the most valuable brands are not always the most visible in social media (for example, Coca Cola is less visible than Microsoft); that social media brands, perhaps not unexpectedly are far more visible than the most valuable brands; and, that Facebook is many magnitudes more visible than all other brands.

\section{Luxury wine brands: the Bordeaux first growths}

Probably the most famous of the world's luxury wine brands are the so-called Bordeaux "first growths" (French: premier crus). These legendary brands, in no particular order, are Château Margaux, Château Latour, Château Lafite-Rothschild, Château Mouton-Rothschild, and Château Haut-Brion (Johnson and Robinson, 2005; Parker, 2003). The original identification of these five brands came from the Bordeaux Wine Official Classification of 1855, an attempt by the French Government at the time to give some structure the Bordeaux wine production. Of all the thousands of wine producers in Bordeaux a list of 61 of the top ranked wines, named the Grand Crus Classés (Great Classified Growths) was created. To be classified was to carry a mark of high prestige, and to be recognized as a first growth carried the highest prestige of all. Initially, there were only four first growths in the 1855 classification, but in 1973 a fifth estate, Château Mouton Rothschild, was promoted to premier cru status.

These wines epitomize not only luxury wine brands, but also luxury brands in general (Berthon et al., 2010). They are expensive - for example, the 2005 Château Lafite-Rothschild currently retails for around $\$ 750$ per bottle. They are rare and exclusive, so hard to come by that they are only sold in specialist wine stores. And they are the kinds of brands that legends are made of. For example, in the novel Sophie's Choice, of Château Margaux the author Styron (1992, p. 151) writes, "[. . . when you live a good life like a saint and die, that must be what they make you to drink (sic) in paradise". In the movie Ratatouille, the character Skinner says to Linguini, "But you would have to be an idiot of elephantine proportions not to appreciate this' 61 Château Latour, and you, Monsieur Linguini, are no idiot. Let us toast your non-idiocy!". We, therefore, chose to study the placement and positioning of the Bordeaux first growths as luxury brands within social media.

\section{The study and methodology}

In order to illustrate our approach to using data from How Sociable to portray similar luxury wine brands in multi-dimensional space, we gathered data on the five Bordeaux first growths by entering their brand names into the How Sociable web site, and having the web site calculate overall visibility scores, as well as visibilities in all 32 social media the site reports on. Next a contingency table was created, with the five Bordeaux first growth brands as columns, and the 32 social media as rows. At this point it was decided to reduce the number of social media to be incorporated into further analysis, for practical reasons. First, for further analysis using correspondence there was a danger that having 32 points on a map would make viewing and interpretation complex and difficult. Although correspondence analysis can easily deal with a large number of rows, as in an example such as this, the resulting map would have been very "busy" and cluttered. Second, on quite a few of the less well-known social media, none of the Bordeaux first 
growth brands were scoring anything at all. There would have been two options here: either to incorporate all thirteen "other" social media into a combined row called "other", or to exclude them. We chose the latter strategy. Our intention was to focus on the most important and most relevant social media, and since the brands being considered here did not even feature in most of these information on them would add little value to a manager's interpretation. In total, 13 social media sites were chosen for the final analysis, namely Google Page Score (Google PS), Twitter, MySpace, Ning, Digg, Ecademy, Yahoo Page Score (Yahoo PS), Facebook Groups (Facebook G), Facebook Pages (Facebook P), Google I, Xing, Linked In, and YouTube Videos (YouTube V). The contingency table was then used as data input for correspondence analysis using Xlstat.

A summary of the scores for each Bordeaux first growth brand in each of the selected social media is shown in Table I, and the overall brand visibility scores for each of the luxury wine brands is shown in Figure 2.

Two points can be made from Table I and Figure 2. First, interpreting a reasonably complex table such as that in Table I can be difficult, as the observer not only wishes to assess where a particular brand is performing well or poorly, but would also want to determine how a brand stacked up to another brand on a particular social medium.

\begin{tabular}{lccccc}
\hline & Margaux & Haut Brion & Lafite & Latour & Mouton Rothschild \\
\hline Google PS & 85 & 76 & 83 & 80 & 71 \\
Twitter & 425 & 245 & 459 & 361 & 347 \\
MySpace & 21 & 12 & 20 & 16 & 14 \\
Ning & 68 & 74 & 60 & 61 & 31 \\
Digg & 38 & 11 & 21 & 32 & 59 \\
Ecademy & 51 & 0 & 102 & 72 & 125 \\
Yahoo PS & 120 & 92 & 66 & 116 & 42 \\
Facebook G & 213 & 235 & 71 & 71 & 71 \\
Facebook P & 504 & 317 & 347 & 504 & 589 \\
Google I & 77 & 57 & 72 & 68 & 64 \\
Xing & 36 & 26 & 51 & 44 & 19 \\
Linked In & 22 & 14 & 22 & 27 & 10 \\
YouTube V & 49 & 50 & 33 & 52 & \\
\end{tabular}

\section{Luxury wine brand visibility}

Table I.

Table of the Bordeaux first growth brands by visibility score in individual social media

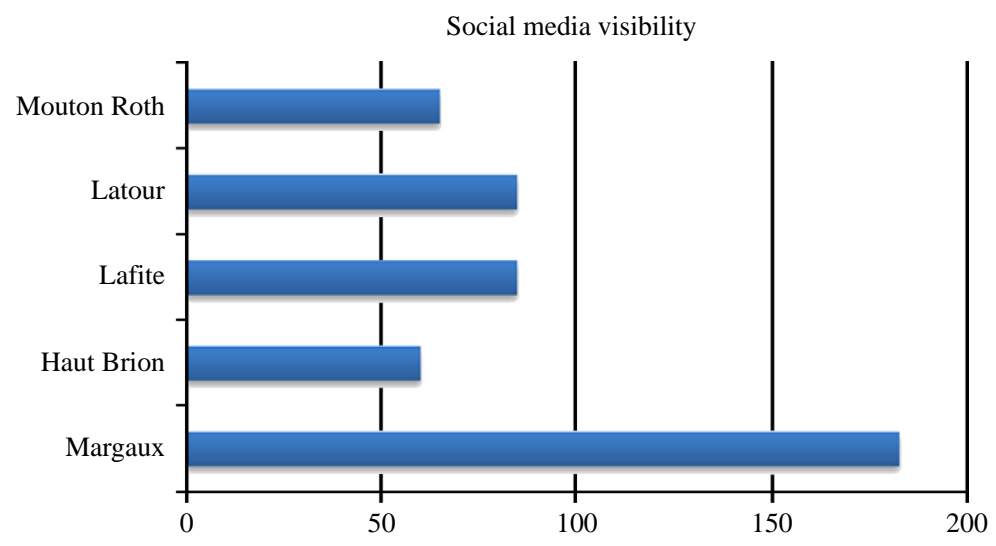

Figure 2.

Overall visibility scores of the five Bordeaux first growth brands 
IJWBR

23,1

28
Being able to construct a picture in which the brands and the social media were portrayed in two-dimensional space would make this much easier. Second, the graph indicates that the most visible first growth wine brand in social media is that of Margaux, followed by Lafite and Latour, and then Mouton Rothschild and Haut-Brion. Château Margaux seems to be markedly "more visible" than the others. However, what the simple bar graph cannot indicate is what accounts for these scores, and where particular brands might either be performing well or poorly. For that purpose, a two-dimensional map might also be better.

\section{Correspondence analysis}

To identify the associations between the Bordeaux first growth brands and the social media visibility indicators, we used correspondence analysis. This is a perceptual mapping technique based on cross-tabulation data that is converted into a joint space map by decomposing the $\chi^{2}$-statistic of the frequency matrix (Bendixen, 1995, 1996; Greenacre, 1993). The perceptual map created through correspondence analysis is useful in uncovering structural relationships between different variables (Inman et al., 2004) and its graphical nature facilitates interpretation of data that would otherwise be difficult to comprehend (O'Brien, 1993). Moreover, Hair et al. (2006) state that correspondence analysis is best suited for exploratory data analysis, and since our study is exploratory in nature, its use in this type of study is appropriate. In order to assess the relative positioning of each of the Bordeaux first growth brands from the perspective of various social media "voices", correspondence analysis permits us to map where each of the brands are relative to the others. Comparison of the different brands is difficult without being able to visualize the social media "voices" that affect each site's ratings relative to others. Hence, the data were subject to correspondence analysis to map the relative positions of each site in low dimensional space.

\section{The results}

The data were analyzed using the XLSTAT package. The results appear in Tables II-IV and a two-dimensional plot, (Figure 3). From the SPSS program ANACOR, additional calculations - row and column quality - augmented the XLSTAT output, and appear in Table IV. These two columns provide a measure of the quality of representation - often referred to as the contribution - of a particular row or column in the retained

Table III.

Dimensional inertia

\begin{tabular}{lccrr}
\hline Eigen values and percentages of inertia & F1 & F2 & F3 & \multicolumn{1}{c}{ F4 } \\
\hline Eigen value & 0.066 & 0.016 & 0.007 & 0.001 \\
Inertia (\%) & 73.438 & 17.593 & 7.676 & 1.292 \\
Cumulative (\%) & 73.438 & 91.032 & 98.708 & 100.000 \\
\hline
\end{tabular}




\begin{tabular}{|c|c|c|c|c|}
\hline Wine brand & Column quality & Social media & Row quality & ury wine \\
\hline Margaux & 0.855 & Google PS & 0.631 & \\
\hline Haut Brion & 0.987 & Twitter & 0.876 & \\
\hline Lafite & 0.932 & MySpace & 0.743 & \\
\hline Latour & 0.224 & Ning & 0.936 & \\
\hline \multirow[t]{9}{*}{ Mouton Roth } & \multirow[t]{9}{*}{0.978} & Digg & 0.972 & \\
\hline & & Ecademy & 0.966 & \\
\hline & & Yahoo PS & 0.606 & \\
\hline & & Facebook G & 0.949 & \\
\hline & & Facebook P & 0.943 & Table I \\
\hline & & Google I & 0.848 & Brands, social media, \\
\hline & & Xing & 0.921 & and attribute quality \\
\hline & & Linked In & 0.494 & of representation in two \\
\hline & & YouTube V & 0.791 & dimensions \\
\hline
\end{tabular}

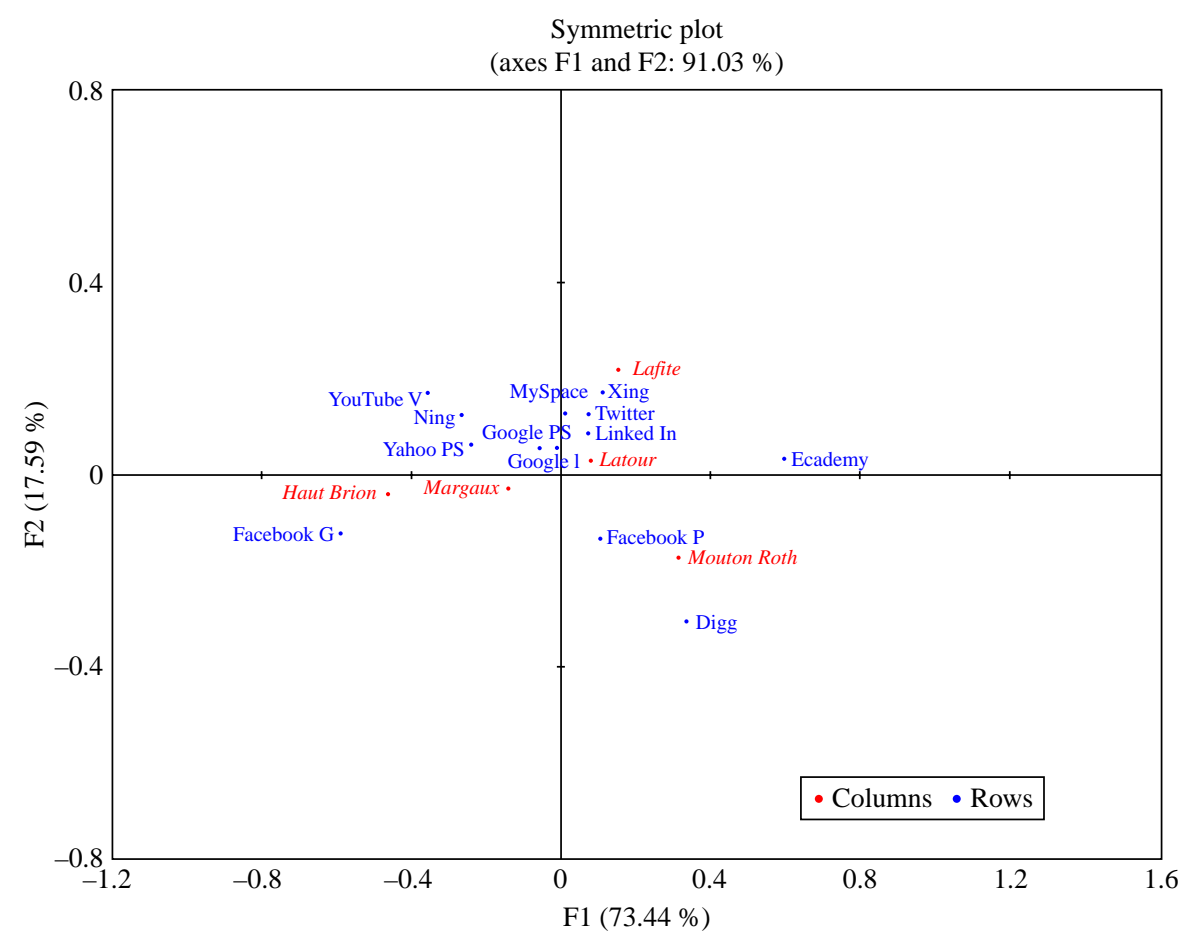

Figure 3. Correspondence analysis map

$n$-dimensional space (two in this study). The quality index ranges between 0 and 1 , with 1 indicating a perfect representation in the retained dimensions. The interpretation of this output follows.

The first step is to establish whether there is dependency between the rows (social media voices) and the columns (wine brands). Table II provides the results from a $\chi^{2}$ analysis of the data and it confirms evidence of strong dependency $(p<0.001)$. 
IJWBR

23,1

30
Alternatively, the square root of the trace (sum of eigenvalues) can also be interpreted as it represents the canonical correlation between rows and columns. This value is 0.30 , which is greater than the suggested cut off value, thus also rendering the results worthy of interpretation (Bendixen, 1996). The second step is to decide upon the number of dimensions to retain for further analysis. Table III provides the inertia report needed for this decision. The first and second dimensions account for 73.438 and 17.593 percent of the inertia, respectively. Together, they account for 91.031 percent of the inertia. Thus, we focus on a two-dimensional solution that should provide an adequate description of the data.

The third step involves noting the quality of the row and column points in the retained dimensions. Analysis of "row quality" and "column quality", Table IV, suggests that most points are fairly well represented, with the exceptions of, in the rows (social media "voices"), Linked-In (total contribution of 0.494) and, in the columns (wine brands), Latour (0.224). Thus, a certain degree of caution should be exercised when interpreting these points in the retained dimensions.

The fourth step involves interpreting the retained dimensions, individually or in combination. One way of doing this would be an interpretation of the asymmetric plots that can result from correspondence analysis as suggested by Bendixen (1996); however, we have followed the approaches of Berthon et al. $(1997,2001)$ in this work. This requires studying the absolute magnitudes and the signs of the co-ordinates for the attributes and the companies as graphically shown in Figure 3. Those with large co-ordinates, positive or negative, play a significant role in determining the dimension, and thus its interpretation (Underhill and Peisach, 1985, p. 53). The dimensions are purely numerical scales that are produced to show relative distance from the centroid in a graphical way. The dimensions can be thought of as artificial variables synthesized from the original data to give the maximum explanation of the differences and similarities between the originally observed values. It is up to the analyst to attribute meaning to the dimensions (Remenyi et al., 1995, p. 143).

In terms of social media "voices", proceeding in a clockwise direction, a number of clusters may be identified. Cluster 1 (top-right quadrant - positive on both dimensions 1 and 2) comprises more formal, business oriented, social media with a focus on networking around the brands; these include Twitter, Linkedin, and Xing. This group might be labeled "business brand networking". Cluster 2 (bottom-right quadrant positive on dimension 1 and negative on dimension 2) comprises Facebook $\mathrm{P}$ and Digg, services that focus on "information" about the various brands. Cluster 3: (bottom-left quadrant - negative on both dimensions 1 and 2) comprises just Facebook G, which is again brand focused but more informal and group orientated. Cluster 4 (top-left quadrant - negative on dimension 1 and positive on dimension 2) comprises two sub clusters. First, a well-differentiated informal, personal social media cluster comprising YouTube, Ning, and Yahoo; and second, a poorly differentiated (on the retained axes) cluster comprising MySpace, Google Pages, and Google I.

In contrast to the social media voices, the brands themselves, partly because there are fewer of them, are more dispersed, displaying less "clustering" in the two retained dimensions. Proceeding in a clockwise direction, Lafite occupies the top right-hand quadrant, with Latour being relatively undifferentiated close to the origin (recall that Latour is the one brand that is poorly represented in the retained dimensions). 
Mouton Rothschild occupies the lower right, whilst Haut Brion lies close to the horizontal axes in the lower left quadrant, with Margaux lying close to the origin.

Looking at the relationship between wine brands and social media voices we can surmise the following associations. First, Lafite is associated with business brand networking, Mouton Rothschild with individuals finding and discussing information about the brand, Haut Brion with enthusiast groups. Finally, Margaux and Latour, being centrally located are relatively undifferentiated in terms of social media voice (indeed, the former is more "visible" in most of the social media than the other four brands).

\section{Limitations, managerial implications and directions for future research}

This paper descries a methodology for simultaneously mapping a number of competing brands in multi-dimensional space, based on their visibility in a number of social media. In overall terms, we were not attempting to provide a treatise on correspondence analysis (there in any case a number of excellent works on that topic, including Greenacre (1993); Bendixen (1996)), so much as to alert the luxury wine marketer to the complex nature of social media, using How Sociable as a tool to gather data on that, and employ correspondence analysis as a device for making comparisons. The paper has limitations in that, obviously, it does not claim to be a definitive study of the positioning of all Bordeaux classified wine brands in social media, but merely selects the five first growth brands within a limited number of social media, as a means of illustration of a technique. The picture obtained here could well have been very different had different, or more brands been chosen, or if other, or additional social media were chosen. Second, a study such as this provides more of a snapshot in time than an ultimate set of results. It may very well be that if the data had been collected at a different time, perhaps a few months earlier or later and then subjected to an analysis that a very different picture would have emerged. The nature of social media is such that their content evolves continuously. Third, the positioning of Bordeaux brands on social media results exclusively from "How sociable" which is a limitation in this case as this method is not controllable by researchers. Data from a third party source such as How Sociable has to be taken at face value - if there are weaknesses in the methods How Sociable uses to gather social media data, or errors in the reporting of this, they are not controllable by outside researchers, and they will obviously be reflected in the results of a study such as this. Fourth, on a technical point, while we used a two-dimensional solution in our interpretation of the correspondence analysis in this instance, it is obvious that a three-dimensional solution is possible from the data. The third dimension in Table III explains a further 7.68 percent of the variation in the data, and might also shed more light on the Chateau Latour brand in the columns. Users should be alert to these factors when they analyze and interpret similar data.

Nonetheless, a number of managerial implications become apparent from the research conducted here. First, it seems as if some of the brands considered did not, at the time the data were gathered, have a clearly defined social media strategy. This is currently understandable because social media are a relatively new phenomenon, but the rapid growth of social media means that this laissez faire approach may not be tenable in the future. While it may be tempting to say that social media are the prerogative of younger consumers, the reality is that social media such as Facebook and Twitter are predominantly used by generation $\mathrm{X}$ and baby boomer consumers today. The UK's leading wine critic "tweets" regularly on Twitter, and has more than 24,000 followers.
Luxury wine brand visibility 
IJWBR

23,1

32

Astute wine brand managers will define the social media that they care most about. Then, they will first think seriously about the kind of official presence they wish to establish in these media (for example, an official fan page on Facebook, regular tweets on Twitter about newsworthy events, and frequent posting of videos concerning the chateau and its activities (e.g. news of vintages, tastings, etc.) on a dedicated YouTube page. Luxury wine brand managers will also regularly monitor non-official content in social media by regular information scanning of social media sites, and having contingency plans in place that will allow them to act and react appropriately to this. They will also monitor social media content and visibility of brands they regard either as competitors or benchmarks. In this instance, sources of data such as How Sociable.com, and tools such as correspondence analysis that permit the simultaneous picturing of brands in multidimensional space might become invaluable tools. Finally, they will also be able to monitor the effectiveness of social media strategies by using data from sources such as How Sociable to track overall brand visibility, and correspondence analysis maps to determine how a particular strategy had moved the particular brand against competitor brands, and with regard to particular social media.

Exploratory studies such as those reported in this paper also opens up a stream of further future opportunities for research. First, it would be wise to find ways of confirming the reliability and validity of data gathered by services such as How Sociable. This might be done by consulting and working directly with these service providers in an effort to gain a better understanding of their methodologies and results. It could also be done by closely monitoring the results for a set of brands over a period, and establishing some kind of test-retest pattern to determine reliability.

Second, the results of secondary data research such as this could be combined with primary data collection in the target markets of the brands concerned. For example, at a qualitative level, researchers might wish to hold online or face-to-face focus groups with users of the various social media sites in order to gather in-depth feedback on their involvement in these media. At a more quantitative level, researchers could analyze the text of the interactions that users have concerning their brands in social media. Researchers such as Opoku et al. (2007a, b), describe tools that can be used to analyze large amounts of text by means of computerized content analysis that could be employed in this regard. For example, if a wine brand noted as a result of our approach here that it was being discussed significantly by viewers of a video clip of their wine on YouTube, this brand could employ a tool such as Leximancer to analyze this content. Leximancer is a relatively simple but powerful data-mining tool that enables a visual depiction and interpretation of complex textual data, which is displayed by means of a concept map showing the main concepts and themes that develop from the brand discussion and the interrelationships between them. The concept map visually details the relative importance of concepts and themes and the strengths between them.

Third, researchers could employ a vast array of tools that are readily available online for social media analysis (many of them free, or at minimal charge, see Barros (2009)) in conjunction with the data from How Sociable, and using tools such as correspondence analysis.

The advent of consumer generated content and its rapid diffusion takes much of the control over messages away from marketers, who find themselves at the mercy of consumers who can create and distribute advertising about their brands (Deighton and Kornfeld, 2007). This makes the management of luxury brands in an era of social media 
not only more difficult, but also even more critical than it has been in the past. Brands can take directions in social media that would have been unlikely if not impossible just five years ago. Brand managers will not fully be able to control the destinies of these brands, but at least they should still be part of, and ideally, direct the conversations that occur around their brands. They will need to use every tool at their disposal. We suggest that the approaches followed in the research presented in this paper will be one tool in the brand manager's arsenal that will assist them in this endeavor.

\section{References}

Arington, M. (2010), "Hitwise says Facebook most popular US site", available at: http:// techcrunch.com/2010/03/15/hitwise-says-facebook-most-popular-u-s-site/ (accessed 15 March 2010).

Barros, S. (2009), "Know your numbers: 10 free web analytics tools for your website", available at: www.penn-olson.com/2009/09/13/know-your-numbers-10-free-web-analytics-tools-foryour-website/ (accessed 15 March 2010).

Bendixen, M. (1995), "Composing perceptual mapping using chi-squared trees analysis and correspondence analysis”, Journal of Marketing Management, Vol. 11 No. 6, pp. 571-81.

Bendixen, M. (1996), "A practical guide to the use of correspondence analysis in marketing research”, Marketing Research, Vol. 1, pp. 16-38, available at: www.xlstat.com/corres3.pdf (accessed 17 March 2010).

Berthon, P.R., Pitt, L.F. and Campbell, C. (2008), "Ad lib: when customers create the ad", California Management Review, Vol. 50 No. 4, pp. 6-30.

Berthon, P.R., Pitt, L.F., Parent, M. and Berthon, J.P. (2010), "Aesthetics and ephemerality: observing and preserving the luxury brand", California Management Review, Vol. 52 No. 1, pp. 45-66.

Berthon, P.R., Pitt, L.F., Ewing, M.T., Ramaseshan, B. and Jayaratna, N. (2001), "Positioning in cyberspace: evaluating telecom websites using correspondence analysis", Information Resources Management Journal, Vol. 14 No. 1, pp. 13-21.

Berthon, P.R., Pitt, L.F., Berthon, J.-P., Crowther, C., Bruwer, L., Lyall, P. and Money, A.H. (1997), "Mapping the marketspace: evaluating industry web sites using correspondence analysis", Journal of Strategic Marketing, Vol. 5 No. 4, pp. 233-42.

Brogan, C. (2010), Social Media 101: Tactics and Tips to Develop Your Business Online, Wiley, Hoboken, NJ.

Daily Telegraph (2008), "Web could collapse as video demand soars", available at: www. telegraph.co.uk (accessed 25 March 2010).

Deighton, J. (2007), Dove: Evolution of a Brand, Harvard Business School Press, Boston, MA.

Deighton, J. and Kornfeld, L. (2007), Digital interactivity: unanticipated consequences for markets marketing, and consumers, working paper, Harvard Business School, Boston, MA, August 2009.

Facebook (2010), "Facebook press room", available at: www.facebook.com/press/info. php?statistics (accessed 25 March 2010).

Greenacre, M. (1993), Correspondence Analysis in Practice, Academic Press, New York, NY.

Hair, J.F., Black, W.C., Babin, B.J., Anderson, R.E. and Tatham, R.L. (2006), Multivariate Data Analysis, 6th ed., Prentice-Hall, Upper Saddle River, NJ.

Inman, J.J., Shankar, V. and Ferraro, R. (2004), "The roles of channel-category associations and geodemographics in channel patronage", Journal of Marketing, Vol. 68 No. 2, pp. 51-71.

\section{Luxury wine brand visibility}


IJWBR

23,1
Johnson, H. and Robinson, J. (2005), The World Atlas of Wine, Mitchell Beazley, London.

Kaplan, A.M. and Haenlein, M. (2010), "Users of the world, unite! The challenges and opportunities of social media”, Business Horizons, Vol. 53 No. 1, pp. 59-68.

Markwell, J.L. (2010), “Our visibility score”, available at: http://howsociable.wordpress.com/2008/ 08/08/our-visibility-score/(accessed March 2010).

O’Brien, T.W. (1993), “Correspondence analysis”, Marketing Research, Vol. 5 No. 4, pp. 54-60.

Opoku, R.A., Pitt, L.F. and Abratt, R. (2007a), "Positioning in cyberspace: evaluating bestselling authors' online communicated brand personalities using computer-aided content analysis”, South African Journal of Business Management, Vol. 38 No. 4, pp. 21-32.

Opoku, R.A., Abratt, R., Bendixen, M. and Pitt, L.F. (2007b), “Communicating brand personality: are the websites doing the talking for food SME's?", Qualitative Market Research, Vol. 10 No. 4, pp. 362-74.

Parker, R.M. Jr (2003), Bordeaux: A Consumer's Guide to the World's Finest Wines, 4th ed., Simon and Schuster, New York, NY.

Rao, S.S., Metts, G. and Mora Monge, C.A. (2003), "Electronic commerce development in small and medium sized enterprises: a stage model and its implications", Business Process Management Journal, Vol. 9 No. 1, pp. 11-32.

Remenyi, D., Money, A.H. and Twite, A. (1995), Effective Measurement and Management of IT Costs and Benefit, Butterworth-Heinemann, London.

Shiels, M. (2010), "YouTube at five -2 bn views a day", available at: http://news.bbc.co.uk/2/hi/ technology/8676380.stm (accessed 19 May 2010).

Steyn, P.G., van Heerden, G., Pitt, L.F. and Boshoff, C. (2008), "Meet the bloggers: some characteristics of serious bloggers in the Asia-Pacific region, and why PR professionals might care about them", Public Relations Quarterly, Vol. 52 No. 3, pp. 39-44.

Stricker, S., Sumner, D.A. and Mueller, R.A.E. (2003), "Wine on the web in a global market: a comparison of e-commerce readiness and use in Australia, California and Germany", paper presented at EFITA Conference, Debrecen, Hungary, July.

Styron, W. (1992), "Sophie's choice”, Vintage International, Vintage Books, New York, NY.

Tapscott, D. and Williams, A.D. (2007), Wikinomics: How Mass Collaboration Changes Everything, Penguin, New York, NY.

Thach, L. (2009), "Wine 2.0 - the next phase of wine marketing? Exploring US winery adoption of wine 2.0 components", Journal of Wine Research, Vol. 20 No. 2, pp. 143-57.

Underhill, L.G. and Peisach, M. (1985), “Correspondence analysis and its application in multi-elemental trace analysis", Journal of Trace and Microprobe Techniques, Vol. 3 Nos 1/2, pp. 41-65.

Yen, Y. (2008), "YouTube looks for the money clip", Fortune, available at: http://techland.blogs. fortune.cnn.com/2008/03/25/youtube-looks-for-the-money-clip/(accessed 25 March 2010).

Zarella, D. (2010), The Social Media Marketing Book, O’Reilly Media, North Sebastopol, CA.

Zhu, Y., Basil, D.Z. and Hunter, G.M. (2009), "The extended website stage model: a study of Canadian winery websites", Canadian Journal of Administrative Sciences, Vol. 26 No. 4, pp. 286-300.

\section{About the authors}

Mignon Reyneke is a PhD Candidate in the Division of Industrial Marketing, eCommerce and Logistics at Lulea University of Technology, Lulea, Sweden. Mignon Reyneke is the corresponding author and can be contacted at: mignon.reyneke@gmail.com 
Leyland Pitt is a Professor of Marketing and the Dennis F. Culver EMBA Alumni Chair of Business at Simon Fraser University, and also Senior Research Fellow at Leeds University Business School in the UK. His work has been published in such journals as California Management Review, Journal of the Academy of Marketing Science, Journal of Advertising, and MIS Quarterly (which he also served as associate editor). His PhDs were awarded by the University of Pretoria, South Africa, and Lulea University of Technology, Sweden.

Pierre R. Berthon is the Clifford Youse Chair of Marketing in the McCallum Graduate School of Business, Bentley University, Waltham, USA. His research is eclectic and has been published in such journals as Sloan Management Review, Journal of Services Research, Journal of the Academy Luxury wine
brand visibility of Marketing Science, Information Systems Research, and the Journal of Advertising Research. His $\mathrm{PhD}$ was awarded by Brunel University/Henley Management College. 